\title{
ANÁLISE QUALITATIVA DO CONTEÚDO MINISTRADO NA DISCIPLINA DE BIOÉTICA NAS FACULDADES DE ODONTOLOGIA BRASILEIRAS
}

\author{
Patricia Elaine Gonçalves, Cléa Adas Saliba Garbin, Artênio José Isper Garbin, Nemre Adas Saliba*
}

\begin{abstract}
Resumo: O estudo consiste em uma análise qualitativa do conteúdo ministrado pela disciplina de Bioética nas Faculdades de Odontologia Brasileiras. A coleta de dados ocorreu por meio de questionários semi-estruturados enviados por e-mail e correspondência. Empregou-se a análise de conteúdo, pela técnica de análise categorial, conforme preconizado por Bardin. Dentre as 182 Faculdades de Odontologia em atividade no Brasil, apenas 57 (31,3\%) apresentam na sua grade curricular a disciplina Bioética. Observou-se que a disciplina é ministrada geralmente no primeiro ou último ano do curso. Os principais assuntos abordados na disciplina são dilemas bioéticos $(76,3 \%)$ que tratam principalmente sobre questôes polêmicas e atuais como clonagem, aborto, transplante de órgãos, atendimento do paciente portador de HIV e ainda sobre o histórico da bioética (65,8\%), fundamentos, princípios e modelos bioéticos (57,9\%). 84,4\% dos professores pesquisados mencionam que a disciplina de bioética desperta interesse nos alunos, por ser atual e estar voltada também para a relaçáo profissional-paciente. Concluiu-se que essa disciplina trata, em seu conteúdo, de temas atuais e polêmicos que influenciam na formação do cirurgião-dentista, pois promove ao mesmo tempo a consciência e a responsabilidade do seu papel frente à atençáo em saúde bucal. Ademais, a mesma deve ser implantada, especificamente, no primeiro ano, em todos os cursos de graduação em Odontologia.
\end{abstract}

Palavras-chave: ensino superior, odontologia, bioética

\section{ANÁLISIS CUALITATIVO DEL CONTENIDO DE LA DISCIPLINA DE BIOÉTICA EN LAS FACULTADES DE ODONTOLOGÍA BRASILEÑAS}

Resumen: El estudio comprende un análisis cualitativo de los contenidos de las clases de bioética en las facultades de odontología. Los datos fueron recolectados a través de cuestionarios semiestructurados enviados por correo electrónico y correspondencia. Empleamos el análisis de contenido y la técnica de análisis por categorías, según lo recomendado por Bardin. Entre las escuelas dentales, 182 en operación en Brasil, sólo 57 (31,3\%) tienen bioética en su currículo. Se observó que la disciplina se da generalmente en el primer ańo o final. Los temas principales de este curso son los dilemas bioéticos (76,3\%), que tratan principalmente sobre cuestiones actuales y controversiales, como la clonación, el aborto, el trasplante de órganos, la atención de los pacientes con VIH y la historia de la bioética $(65,8 \%)$, los fundamentos, principios y modelos de la bioética $(57,9 \%)$. El 84,4\% de los docentes encuestados mencionó que la disciplina de la bioética despierta el interés en los estudiantes, por ser actual y por redundar en la relación profesional-paciente. Se concluye que esta disciplina trata de temas actuales y polémicos que influyen en la formación del cirujano dentista, pues promueve la conciencia y la responsabilidad de su papel frente a la atención en salud bucal. Además, la misma debe ser implantada, específicamente, en primer año en todos los cursos de pregrado en Odontología.

Palabras clave: educación superior, odontología, bioética

\section{QUALITATIVE ANALYSIS OF CONTENT MINISTERED ON BIOETHICAL DISCIPLINE ON BRAZILIAN DENTAL SCHOOLS}

\begin{abstract}
The study consists on a qualitative analysis of content ministered by Bioethical discipline on Brazilian Dental Schools. Data collect occurred by semi-structured questioners send by e-mail and correspondence. It was used content analysis by categorical analysis technique, according to Bardin. Among 182 Schools, just 57 (31.3\%) shows Bioethical Discipline. It was observed that the discipline is ministered on the first or last year of course generally. Principal subjects broached are bioethical dilemma (76.3\%) with polemics questions and others actual like abortion, clone, organs transplant, attendance of patient porter of HIV and bioethical historic (65.8\%), bioethical fundaments, principles and models (57.9\%). 84.4\% researched professors, said that bioethical discipline awake interesting on students because it actual and it's face to patient-professional relation too. It was possible to conclude that bioethical discipline treat in its content some actual and polemic themes that influence dental surgeon formation because promote him conscience and responsibility of him role front attention at oral health, and so, this discipline should be implanted, specifically in the first year of all Dentistry graduation courses.
\end{abstract}

Key words: Education, Higher, Dentistry, Bioethics

* Programa de Pós-graduação em Odontologia Preventiva e Social pela Faculdade de Odontologia de Araçatuba - UNESP, Brasil

Correspondência: pattysp03@yahoo.com.br 


\section{Introdução}

Um novo perfil para o egresso de Odontologia passa a ser exigido, direcionado para valores de cidadania, apresentando alguns conceitos importantes e fundamentais para se tornar multiplicador de conhecimentos éticos, sociais e principalmente humanos, pois, atualmente, muitos profissionais são preparados segundo um elevado padrão de qualificação, mas sem levar, em sua formaçâo prática, as condiçôes sócio-econômicas como determinantes de doenças bucais(1).

A Resolução do Conselho de Educação Superior do Conselho Nacional de Educação - CES/CNE n³, que trata das Diretrizes Curriculares Nacionais do Curso de Graduação em Odontologia destaca como perfil, o egresso com formação generalista, humanística, crítica e reflexiva para atuar em todos os níveis de atenção à saúde, com base no rigor técnico e científico. Esse deverá estar capacitado ao exercício das atividades referentes à saúde bucal da população, pautado em princípios éticos, legais e na compreensão da realidade social, cultural e econômica do seu meio, dirigindo sua atuação para a transformação da realidade em benefício da sociedade $(2: 1)$.

Com isso, a educação atual exige a aplicação da pedagogia de competências, que ao adquiri-las garante a promessa de empregabilidade e habilidades para ser e agir como cidadãos(3).

Por isso, no curso de Odontologia deve-se conscientizar o aluno durante o processo de competências teóricas e técnicas, proporcionando momentos de reflexáo sobre o seu papel, dentro de uma contextualização do seu processo de trabalho a partir da autopercepção pessoal, desenvolvendo assim, o seu potencial intelectual e afetivo, que o capacite para adquirir as habilidades para atenção do doente, e o habilite para descobrir em sua função profissional a autêntica dimensão social que cabe a ele como cidadão responsável(4).

Nas diretrizes Curriculares de 2002, os conteúdos essenciais para o curso de Odontologia estáo divididos em conteúdos que envolvem as Ciências Biológicas e da Saúde, Ciências Humanas e Sociais e Ciências Odontológicas. É nas Ciências Sociais e Humanas que se incluem "os conteúdos referentes às diversas dimensões da relação indivíduo/sociedade, contribuindo para a compreensão dos determinantes sociais, culturais, comportamentais, psicológicos, ecológicos, éticos e legais, nos níveis individual e coletivo, do processo saúde-doença” (2:3). És justamente nesse campo está inserida a disciplinas de Bioética, que é objeto de estudo deste trabalho.

Apesar de ser, a Bioética, extremamente ampla e tratar de temas polêmicos como clonagem, aborto, eutanásia e estudo com células-tronco embrionárias, na Odontologia, o estudo dos seus aspectos não pode ser negligenciado, principalmente por sua importância para o bom andamento e sucesso do tratamento odontológico(5).

\section{Objetivos}

Este estudo consiste em uma análise qualitativa do conteúdo ministrado pela disciplina de Bioética nas Faculdades de Odontologia Brasileiras

\section{Material e método}

O nosso estudo é do tipo exploratório, descritivo, transversal.

Inicialmente, foi realizada uma pesquisa, na página eletrônica do Ministério da Educação e Cultura (MEC), mais precisamente na página do Instituto Nacional de Estudos e Pesquisas Educacionais (INEP) para tomar conhecimento do número de faculdades de Odontologia em funcionamento no Brasil e suas respectivas Instituições de Ensino Superior (IES). Para confirmar a existência da disciplina Bioética, entrou-se em todos os sites institucionais em busca da matriz ou grade curricular. $\mathrm{Na}$ instituição em que não foi possível por esse meio, os coordenadores foram contatados para sanar as dúvidas. Para se informar sobre a existência da disciplina na instituição, foram realizadas três tentativas por e-mail e duas por correspondência, com o propósito de alcançar toda a população de estudo. Foi enviado ao coordenador de cada instituição, por e-mail ou correspondência um ofício, expondo os objetivos da pesquisa e solicitando a permissão para entrar em contato com o(s) docente (s) da disciplina estudada. O período de obtenção dos dados foi de agosto de 2007 até fevereiro de 2008.

A coleta de dados ocorreu através da elaboração e aplicação de um questionário. Este continha questôes abertas e fechadas que segundo De Kelete e Roegiers(6:35), designam como questionário de inquérito "...um estudo de um tema preciso junto de uma população, a fim de precisar certos parâmetros". 
Atendendo a Resolução 196/96 do Conselho Nacional de Saúde e suas resoluçóes complementares, o projeto foi submetido e aprovado pelo Comitê de Ética em Pesquisa da Faculdade de Odontologia de Araçatuba UNESP sob parecer n. 2006-01469. Foi enviado, junto com o instrumento de coleta, o Termo de consentimento livre e esclarecido que esclarecia sobre a anuência da sua participação, objetivos, metodologia, a manutenção do sigilo de suas identidades (apesar de não ser solicitada a identificação dos respondentes) e da publicação dos dados obtidos com o presente trabalho.

Os dados obtidos foram informatizados. Para tal, foi confeccionado um banco de dados, utilizando-se o programa EPIINFO 3.2, programa para Windows e, por meio desse, foi realizado o levantamento de freqüência dos dados referente às questóes fechadas. Para as questôes abertas foi realizada a análise de conteúdo preconizada por Bardin(7), utilizando a técnica de categorizaçáo temática. Esta define as categorias como rubricas ou classes, as quais reúnem um grupo sob um título genérico. As respostas foram lidas para identificar os problemas apontados e, o conjunto desses, formou uma grade temática de categorias de análise para a leitura transversal de todos os depoimentos, ou seja, cada relato foi lido e classificado segundo as categorias registradas(8).

\section{Resultados}

Verificou-se que há 182 Faculdades de Odontologia em atividade no Brasil, ou seja, Faculdades que apresentam o curso de odontologia em atividade.
A princípio foram enviados 180 (cento e oitenta) e-mails que corresponde ao total das as faculdades que apresentavam sites; foi feito contato com o coordenador do curso via internet, para enviar o instrumento de coleta para o professor responsável pela disciplina estudada. Foram realizadas três tentativas por esse meio. Simultaneamente enviou-se 2 (duas) cartas, que corresponde aquelas instituições que não apresentavam nenhum tipo de contato eletrônico. Houve retorno de 62 e-mails $(34,5 \%)$ e de 1 carta (50\%). Depois dessas tentativas, foram realizadas mais 2 tentativas por cartas para aquelas instituiçóes que não haviam respondido, somando 109 cartas, obtendo dessas, apenas 10 cartas $(9,2 \%)$, totalizando um percentual de $40,1 \%$ de resposta à pesquisa.

Dentre as faculdades analisadas $(\mathrm{n}=182)$, apenas 57 $(31,3 \%)$ apresentavam na sua grade curricular a disciplina Bioética, sendo 23,7\% particulares e 54,3\% públicas. Destas, $54,4 \%$ a nomenclatura da disciplina era Bioética. Já os outros $46,4 \%$, a disciplina era denominada de Deontologia, Odontologia Legal e Bioética, Deontologia e/ou Odontologia Legal, Saúde Bucal Coletiva, Orientação profissional, Odontologia Preventiva e Social e Seminários Integrados. Do total de 57 instituições, conseguiu-se obter a resposta de 38 Instituições de Ensino Superior, o que corresponde a $66,7 \%$.

Observou-se que a disciplina é ministrada geralmente no primeiro $(28,6 \%)$ ou último ano do curso $(33,9 \%)$ (Figura 1). Quanto ao gênero do docente que ministra a disciplina, 56,1\% são homens e $95 \%$ são formados em Odontologia. Outros 5\% são teólogos ou advogados.

Figura 1 - Distribuição percentual das Faculdades de Odontologia Brasileiras segundo o ano letivo que a disciplina Bioética é ministrada. Brasil, 2008.

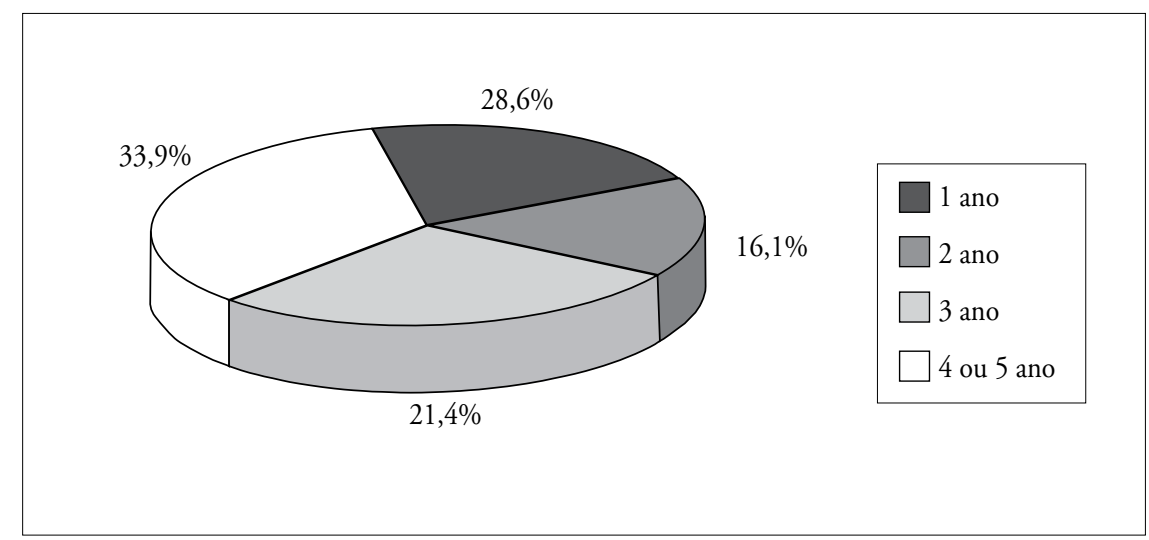


Quanto à qualificação desses docentes, observou-se que apenas $5 \%$ apresentam graduação em Odontologia. Já 2,5\% possuem especialização, 45\% Mestrado, 45\% Doutorado e 2,5\% Livre-docência. Sendo que todos são graduados nas diversas áreas da Odontologia.

Referente aos principais assuntos abordados na disciplina de Bioética, foram citados os dilemas bioéticos $(76,3 \%)$ que tratam principalmente sobre questóes polêmicas e atuais como clonagem, aborto, transplante de órgãos, atendimento do paciente portador de HIV; histórico da Bioética $(65,8 \%)$; fundamentos, princípios e modelos bioéticos (57,9\%)(Quadro 1).

Quadro 1 - Distribuição da freqüência absoluta e relativa dos assuntos abordados na disciplina de Bioética nas Faculdades de Odontologia Brasileiras, segundo os docentes entrevistados. Brasil, 2008.

\begin{tabular}{|l|c|c|}
\hline Categorias & n & \% \\
\hline Dilemas Bioéticos & 29 & 76,3 \\
\hline Histórico da Bioética & 25 & 65,8 \\
\hline Fundamentos, Modelos e princípios bioéticos & 22 & 57,9 \\
\hline Relaçáo Profissional-paciente & 17 & 44,7 \\
\hline Pesquisa & 13 & 34,2 \\
\hline Resoluçáo 196/96 & 12 & 31,6 \\
\hline TCLE (termo de consentimento livre e esclarecido) & 8 & 21,1 \\
\hline $\begin{array}{l}\text { CEP/CONEP (Comitê de Éticas em Pesquisa e } \\
\text { Conselho Nacional de Ética e Pesquisa) }\end{array}$ & 5 & 13,2 \\
\hline
\end{tabular}

* A soma da porcentagem poderá ser maior que $100 \%$ pois a mesma resposta poderia ser classificada em mais de uma categoria. A freqüência relativa foi calculada sobre o total de 38 respondentes.

Dentre os professores pesquisados, $84,4 \%$ mencionam que a disciplina de Bioética desperta interesse nos alunos, pois é atual $(51,7 \%)$ e por tratar sobre a relação profissional-paciente $(51,7 \%)$ (Quadro 2). Ademais, os docentes relatam que mais de $75 \%$ dos alunos comparecem às aulas.

Quadro 2 - Distribuição da freqüência absoluta e relativa segundo o motivo de interesse dos alunos frente à disciplina de Bioética, na percepçáo dos os docentes entrevistados. Brasil, 2008.

\begin{tabular}{|l|c|c|}
\hline Categorias & n & $\%$ \\
\hline $\begin{array}{l}\text { Atividade prática - "realidade da futura clinica e } \\
\text { responsabilidade social" }\end{array}$ & 15 & 51,7 \\
\hline $\begin{array}{l}\text { Atualidades - "experimentos na área de biotecnologia } \\
\text { e genética" }\end{array}$ & 15 & 51,7 \\
\hline $\begin{array}{l}\text { Paradigmas Bioéticos - "por fazê-los pensar, discutir } \\
\text { temas que geram controvérsias(aborto, eutanásia, } \\
\text { pesquisa com células troncos, etc) }\end{array}$ & 13 & 44,8 \\
\hline
\end{tabular}

* A soma da porcentagem poderá ser maior que $100 \%$ pois a mesma resposta poderia ser classificada em mais de uma categoria. A freqüência relativa foi calculada sobre o total de 29 respondentes.
Sobre as sugestóes dos professores para a disciplina de Bioética, são mencionadas que a mesma deve apresentar interdisciplinaridade e aplicabilidade $(57,7 \%)$ tanto nos cursos de graduaçáo (Quadro 3) como nos cursos de pós-graduação (50\%)(Quadro 4).

Quadro 3 - Distribuição da frequêencia absoluta e relativa das sugestôes para a disciplina de Bioética no curso de graduaçáo em Odontologia, segundo os docentes entrevistados. Brasil, 2008.

\begin{tabular}{|l|c|c|}
\hline Categorias - Sugestóes & n & $\%$ \\
\hline $\begin{array}{l}\text { Aplicabilidade e interdisciplinaridade - "Que } \\
\text { haja simpósios e a presença da discussáo bioética em } \\
\text { momentos clinicos" }\end{array}$ & 15 & 57,7 \\
\hline $\begin{array}{l}\text { Aumento da carga horária - "aumentar a } \\
\text { carga horária para poder proporcionar discussöes } \\
\text { interdisciplinares" }\end{array}$ & 7 & 26,9 \\
\hline $\begin{array}{l}\text { Obrigatoriedade - "deve ser lecionada como uma } \\
\text { matéria obrigatória aos moldes da pós-graduação lato } \\
\text { sensu (CFO)" }\end{array}$ & 4 & 15,4 \\
\hline $\begin{array}{l}\text { Capacitação docente - "ser mais valorizada pelos } \\
\text { demais professores" }\end{array}$ & 4 & 15,4 \\
\hline
\end{tabular}

* A soma da porcentagem poderá ser maior que $100 \%$ pois a mesma resposta poderia ser classificada em mais de uma categoria. A freqüência relativa foi calculada sobre o total de 26 respondentes.

Quadro 4 - Distribuição da frequiência absoluta e relativa das sugestốes para a disciplina de Bioética no curso de pós-graduaçáo em Odontologia, segundo os docentes entrevistados. Brasil, 2008.

\begin{tabular}{|l|c|c|}
\hline Categorias - Sugestóes & n & $\%$ \\
\hline $\begin{array}{l}\text { Aplicabilidade e interdisciplinaridade - "que } \\
\text { sejam destas mesas de discussáo com a presença de } \\
\text { profissionais de áreas diferentes, direito, genética, } \\
\text { infectologia, etc." }\end{array}$ & 11 & 50 \\
\hline $\begin{array}{l}\text { Obrigatoriedade - "muitos cursos não abordam esse } \\
\text { assunto tão importante" }\end{array}$ & 10 & 15,4 \\
\hline $\begin{array}{l}\text { Aumento da carga horária - "a carga horária } \\
\text { é extremamente pequena e não há tempo para } \\
\text { apresentar pontos cruciais" }\end{array}$ & 3 & 13,6 \\
\hline $\begin{array}{l}\text { Capacitação docente - "que seja ministrada por } \\
\text { quem realmente esteja preparado." }\end{array}$ & 3 & 13,6 \\
\hline
\end{tabular}

* A soma da porcentagem poderá ser maior que $100 \%$ pois a mesma resposta poderia ser classificada em mais de uma categoria. A freqüência relativa foi calculada sobre o total de 22 respondentes.

\section{Discussáo}

Um processo de investigação que usa a técnica do inquérito apresenta como desvantagem "a pequena percentagem dos questionários que voltam..." (9:179). Conforme observado neste estudo, apenas $40,1 \%$ das instituiçóes de ensino responderam ao inquérito. $\mathrm{O}$ envio pelo e-mail foi o que surtiu mais efeito. 
Quanto à devoluçáo dos questionários respondidos, Fox (10) refere que poucas vezes o número de questionários recolhidos ultrapassa os $50 \% \mathrm{e}$, em particular, na investigação social não é maior do que $30 \%$. Já Pinheiro e Silva(11) obtiveram uma taxa de retorno de $30 \%$ e Zilbovicius(12), em seu estudo com envio de questionários a Secretárias de Saúde do Estado de Sáo Paulo, teve um retorno de $58,4 \%$. No presente estudo a porcentagem de questionários respondidos foi de $40,1 \%$, que se pode considerar dentro das boas expectativas.

Santos e Rumel(13) enviaram 6.000 questionários por via postal aos cirurgióes-dentistas do Estado de Santa Catarina, 506 (8,43\%) retornaram. O mesmo ocorreu nesta pesquisa, pois dos 109 questionários enviados via postal, obteve-se apenas resposta de $9,2 \%$.

Dentre as faculdades que apresentavam o ensino da Bioética (57), conseguiu-se obter a resposta de 38 Instituição de Ensino Superior (66,7\%).

Em um estudo realizado na Argentina, Guerra(14) observou que havia a presença da Bioética em apenas 16,6\% dos currículos das Faculdades de Odontologia. Já Musse et al.(15) analizaram 45 Faculdades de Odontologia no estado de Sáo Paulo, Brasil, constataram que $8,8 \%$ das instituições possuíam a disciplina Bioética. No presente estudo, verificou-se que $31,3 \%$ das Faculdades Brasileiras possuem a disciplina Bioética. Guerra(14) menciona que esta disciplina é tratada apenas como uma unidade em outras disciplinas ministradas, como Deontologia e/ou Odontologia Legal, Orientação Profissional, entre outras. Diante desses dados, se deve enfatizar que a falta do ensino da Bioética nas Faculdades traz um comprometimento na formação do acadêmico, quanto ao seu papel perante a sociedade.

Sabe-se que toda a proposta de ensino deve possibilitar ao aluno aquisição de competências nas dimensóes do saber (domínio teórico-conceitual), do saber fazer (habilidades básicas para o exercício da prática profissional), do saber ser (desenvolvimento de atitudes necessárias para o relacionamento humano e ético da prática) e do saber conviver, com os avanços tecnológicos e com as mudanças do mundo do trabalho(16). Embora o ensino de Odontologia se caracterize como educação vocacional "diretiva", que tenta levar o estudante à aquisição de conhecimentos, habilidades e atitudes concentradas em torno de sua prática(17), o ensino da disciplina Bioética na graduação se tornam importantes, pois não se deve confundir a Bioética atual como uma reformulação da ética filosófica tradicional ou uma nova deontologia profissional(18), de acordo com 51,7\% dos entrevistados que citaram tratar a disciplina de assuntos atuais e o tema da atividade prática.

Alguns autores ressaltam que a Bioética, no tratamento odontológico, deve ser inserida no campo acadêmico do futuro cirurgião-dentista. Ao realizar isso, não se nega à educação o modelo de profissional já estabelecido, mas o aprimora, para que haja a compreensão do valor do relacionamento profissional/paciente, que resultaria em um ganho bilateral, e não apenas unilateral, como se observou por longos períodos(19-23), corrobando com este estudo, pois $44,7 \%$ citaram a relação profissionalpaciente como assunto abordado na Bioética.

Diante disso, Musse et al.(15) averiguou que a Bioética deveria ser introduzida ainda no ciclo básico da formação nível superior, mas verificou-se, nos cursos de Odontologia pesquisados, que a disciplina era oferecida apenas na metade final do curso, semelhante a este estudo, em que se observou 33,9\% das IES oferecem a disciplina no último ano do curso, momento em que esses conhecimentos já deveriam estar solidificados, pois influenciarão na conduta dos futuros profissionais; sabe-se que o acadêmico em Odontologia destina a maior parte do tempo no aprimoramento de técnicas e procedimentos. Porém, Silva(24) encontra uma realidade diferente nas Faculdades de Medicina de Portugal, nas quais a disciplina Bioética desenvolve-se, progressivamente, em todas as disciplinas e de responsabilidade dos respectivos regentes. Essa Interdisciplinaridade da Bioética foi sugerida por $57,7 \%$ dos docentes pesquisados para que o acadêmico, no último ano, seja capaz de assumir uma postura multidisciplinar, promovendo assim uma boa inter-relação das diversas áreas do conhecimento(25).

Quanto aos temas abordados, Berlinguer(26) enfatiza que ao se pensar Bioética, normalmente se pensa em "situações limites" como a eutanásia, a fecundação assistida e DNA recombinante conforme 76,3\% dos pesquisados mencionaram. Porém, a rotina da prática odontológica também é marcada por conflitos éticos como o comércio de dentes humanos, as pesquisas que descobrem novas técnicas e biomateriais, citada por apenas $34,2 \%$ dos entrevistados, ou seja, poucos têm conhecimento desses temas, como também o tema 
da humanização e o respeito aos princípios éticos na relação entre profissional e paciente, mencionado por apenas $44,7 \%$ dos entrevistados. Assim, o profissional deve ser formado dentro dessa realidade para apresentar uma visão integral do paciente, incorporando a sua formação à competência ética(8).

Em relação ao interesse dos alunos pela disciplina, os docentes entrevistados ressaltam que o motivo é que ela é atual $(50 \%)$ e por ser tratar o tema da relação profissional-paciente $(53,6 \%)$. Diante disso, Stêvão et al(27) enfatizam que o profissional torna-se um solucionador de problemas, promovendo ou restabelecendo a saúde de seus pacientes.

Ademais, o desenvolvimento e a crescente incorporação de tecnologias aplicadas à saúde trazem aos profissionais situaçóes e questionamentos sobre os quais náo existe uma reflexão estabelecida em suas corporaçóes(28), como o atendimento do paciente portador de HIV, pesquisas com células troncos embrionárias, etc. Por isso, a Bioética emergiu como um movimento interdisciplinar para questionar e refletir sobre as questóes concretas que a sociedade atual está vivenciando.

Com isso, a Bioética deve apresentar aplicabilidade e interdisciplinaridade, pois com o ensino fragmentado em especialidades e apenas a citação de valores éticos e morais nas universidades, forma-se um profissional que automaticamente categoriza o paciente de acordo com as necessidades, sem avaliar valores superiores à uma simples dor de dente, etc. Por isso, conceitos sócio-político-econômicos são importantes na formação do profissional de saúde, ou seja, os princípios de autonomia, não-maleficência, beneficência, justiça e outros que permanecem muitas vezes apenas em atividades de pesquisa(29).

Pelo fato da Bioética ser, um tema que mobiliza as pessoas de maneira geral e, que pode envolver conflitos e interesses diversos, muitos profissionais consideramse aptos a discutir e ensina-la. Todavia, neste estudo, docentes pesquisados mencionam a necessidade da capacitação dos profissionais tanto para o ensino na graduação $(15,4 \%)$ como na pós-graduação $(13,6 \%)$, pois a apresentaçáo de temas bioéticos deve ocupar todos os momentos possíveis da formação de todo o profissional de saúde, pois é grande a complexidade que une educação, saúde e bioética, já que é pequena ou nula a tradiçáo de estudos interdisciplinares(30-32).

Concluiu-se que a disciplina de Bioética trata em seu conteúdo temas atuais e polêmicos que influenciam na formação do cirurgiáo-dentista, pois promove ao mesmo a consciência e a responsabilidade do seu papel frente à atenção em saúde bucal, ademais, a mesma deve ser implantada, especificamente, no primeiro ano, em todos os cursos de graduação em Odontologia.

\section{Referências}

1. Rodrigues RPCB. Análise da área da saúde coletiva nas estruturas curriculares dos cursos de odontologia do Brasil. [Disertación de Maestria]. São Paulo: Universidad Estadual Paulista: Facultad de Odontología de Araçatuba; 2005.

2. Brasil. Ministério da Educação e Cultura. Conselho Nacional de Educação. Resolução CNE/CES 3/2002. Diário da União, 4 de mar. 2002. Disponível em: http://dtr2002.saude.gov.br/sesu/ftp/resolucao/03020odontologia.doc Acesso em: 8 jun 2006.

3. Guerra ELA. O ensino superior de administração no Brasil: desafios do novo milênio. Disponível em: http://www.agrad. com/angrad/pdfs/xii_enangrad/O\%20ensino\%20superior\%20de\%Administracao\%20no\%20Brasil.pdf. Acesso em: 23 jun.2006.

4. Costa AMD, Costa JRV, Costa MD, Costa RD, Botrel TEA. Contribuição do perfil do aluno de graduação em Odontologia para a redefinição dos recursos usados pelo professor no processo ensino-aprendizagem. Revista da Faculdade de Odontologia de Lins 2002; 14(1): 30-34.

5. Gonçalves PE, Grabin CAS, Garbin AJI, Moimaz SAS, Oliveira RN. Evaluación del conocimiento de los cirujanos dentistas sobre aspectos bioéticos del tratamiento odontológico. Avances en Odontoestomatología 2007; 23(1): 135-140.

6. De Ketele JM, Roegiers X. Metodologia da recolha de dados. Lisboa: Instituto Piaget; 1999.

7. Bardin L. Análise de conteúdo. Lisboa: Ediçōes 70; 1994.

8. Gonçalves ER, Verdi MIM. Os problemas éticos no atendimento a pacientes na clínica odontológica de ensino. Ciência \& Saúde Coletiva 2007; 12(3): 755-764.

9. Lakatos E, Marconi M. Fundamentos de metodologia cientifica. São Paulo: Editora Atlas S.A.; 1985. 
10. Fox D. El proceso de investigación en educación (2a ed.) Pamplona: Ediciones Universidad de Navarra; 1987.

11. Pinheiro A, Silva B. A Estruturação do Processo de Recolha de Dados On-Line. In Actas da X Conferência Internacional Avaliação Psicológica, Formas e Contextos. Braga: Psiquilíbrios Ediçōes; 2004: 522-9.

12. Zilbovicius C. A saúde bucal e o Sistema Único de Saúde: integralidade seletiva em uma conjuntura neoliberal. [Disertación de Maestria]. 2005. Universidad de São Paulo: Facultad de Odontología. 111 p.

13. Santos JC, Rumel D. Emergência médica na prática odontológica no Estado de Santa Catarina: ocorrência, equipamentos e drogas, conhecimento e treinamento dos cirurgiôes-dentistas. Ciência \& Saúde Coletiva 2006; 11(1): 183-190.

14. Guerra RA. Bioética en la malla curricular de odontología. Acta Bioethica 2006; 12(1):49-54.

15. Musse JO, Boing AF, Martino FS, Silva RHA, Vaccarezza GF, Ramos DLP. O ensino da bioética nos cursos de graduaçáo de Odontologia do estado de São Paulo. Arquivos Ciências da Saúde 2007; 14(1): 13-16.

16. Iochida LC, Batista NA. O ensino da clínica médica: situação atual, perspectiva e desafios. Revista Brasileira Clínica Terapêutica 2002; 28(4): 142-145.

17. Secco LG, Pereira MLT. Formadores em Odontologia: profissionalização e desafios político-estruturais. Ciência \& Saúde Coletiva 2004; 9(1): 113-120.

18. Lolas F. La bioética en el contexto de los programas globales de salud. Revista Panamericana de Salud Pública 1999; 6(1): 65-68.

19. Comes JCM. O atual ensino da ética para os profissionais de saúde e seus reflexos no cotidiano do povo brasileiro. Bioética 1996; 4(1): 39-42.

20. Dummett CO. Ethics and bioethics in dentistry. Journal California Dental Association 1994; 22(10): 30-42.

21. Manji I. Is dentistry in trouble with ethics? Journal Canadian Dental Association 1994; 60(9): 771-773.

22. Odom JG, Beemsterboer PL, Pate TD, Haden NK. Revisiting the status of dental ethics instruction. Journal Dental Education 2000; 64(11): 772-774.

23. Graham BS. Educating Dental Students About Oral Health Care Acess Disparities. Journal Dental Education 2006; 70(11): 1208-1211.

24. Silva JR. O ensino da Bioética nas Faculdades de Medicina Portuguesas. Bioética 2003; 11(2): 43-50.

25. Kenny NP. Bioethics and Canadian Dentistry. Journal Canadian Dental Association 1997; 63(9): 690-694

26. Berlinguer G. Questóes de vida: ética, ciência e saúde, São Paulo: APCE/HUCTEC/CEBES; 1993.

27. Stêvão ELL, Valcanaia TDC, Silva JJ. A Bioética e o processo ensino-aprendizagem na cirurgia e traumatologia bucomaxilofacial. $B C I$ 1998; 5(1): 9-13

28. Taquete SR, Rego S, Schramm FR, Soares LL, Carvalho SV. Situaçôes eticamente conflituosas vivenciadas por estudantes de medicina. Revista Associação Medica Brasileira 2005; 51(1): 23-28.

29. Corsino BV, Pathhoff DE. The ethical and practical asoects of acceptance and Universal patient acceptance. Journal Dental Education 2006; 70 (11): 1199-1201

30. Ferreira HM, Ramos LH. Diretrizes curriculares para o ensino da ética na graduação de enfermagem. Acta Paulista de Enfermagem 2006; 19(3): 328-331.

31. Rosito MMB. Os modos de existir da bioética entre os saberes da saúde e da educação. Mundo Saúde (1995) 2005; 29(3): 359-363.

32. Siqueira J E. O ensino da Bioética no curso médico. Bioética 2003; 11(2): 33-42.

Recibido: 30 de octubre de 2008

Aceptado: 12 de marzo de 2009 